Адрес статьи / To link this article: http://cat.ifmo.ru/ru/2018/v3-i1/133

\title{
Психологическая классификация компьютерных игр
}

\author{
И.М. Кыштымова, С.Б. Тимофеев
}

\author{
Иркутский государственный университет, Россия \\ info@creativity.ru, edge132@mail.ru
}

\begin{abstract}
Аннотация. Авторы определяют компьютерную игру как многоуровневую и многокомпонентную систему, компоненты и уровни которой могут обладать различной степенью тесноты связей. На основе этого выдвигается предположение о том, что классификации, концентрирующиеся на отдельных компонентах игры, мало эффективны для изучения психологического влияния конкретных игр на личность геймеров. Отсутствие универсального классификационного конструкта, позволяющего осуществлять дифференцированный психологический анализ компьютерных игр обусловил актуальность исследования. Предлагаемая классификационная модель, состоит из слабо связных между собой компонентов с разной степенью выраженных в большинстве существующих игр. Модель представлена семью содержательными уровнями: двумя базовыми, свойственными для всех игр, и пятью вариативными. В состав уровней входят тридцать два компонента, степень выраженности которых может определять классификационные характеристики игры.
\end{abstract}

Ключевые слова: компьютерная игра, классификация, система, компоненты, геймер

Важность разработки психологической классификации компьютерных игр связана с их широчайшей распространенностью, повышением удельного веса в коммуникативном развивающем пространстве, малой изученностью особенностей влияния игровой активности на геймеров, противоречивостью научных данных о психологических трансформациях игроков, неполнотой представленных в научной литературе психологически значимых дифференциальных признаков компьютерных игр, позволяющих строить и верифицировать теоретически обоснованные гипотезы о характере их развивающего или трансформирующего психику потенциала.

Компьютерная игра представляет собой многоуровневую многокомпонентную систему. При этом ее уровни: нарративный, геймплейный, сеттинговый, морально-нравственный и другие - могут разворачиваться как параллельно, так и независимо друг от друга и иметь как непосредственную, так и опосредованную другими компонентами связь. Поэтому классификации, имеющие одно или лишь несколько оснований, видятся нам непродуктивными и не отвечающими динамичным темпам развития игровой индустрии. Критический анализ структурных моделей компьютерных игр представлен в [1]. Сложность построения психологической классификации компьютерных игр обусловлена, во-первых, особой природой виртуального мира, опосредующего психическую активность игрока; во-вторых, необходимостью междисциплинарного и полипарадигмального подходов к решению поставленной задачи. Методологическим основанием 
исследования психологической структуры игр явились положения культурно-исторической психологии о природе опосредствования, социального конструкционизма о моделировании реальности и психосемиотики, в рамках которых созданы подходы к анализу полизнаковых текстов.

Предлагаемая классификационная модель состоит из слабо связанных между собой компонентов, с разной степенью выраженных в компьютерных играх, что позволяет считать ее универсальным и гибким инструментом для определения влияния разных типов игр на геймеров.

Дизайн модели представлен семью содержательными уровнями, два из которых являются базовыми и присущи всем видеоиграм, а пять вариативны. В состав выделенных уровней входят тридцать два компонента, степень выраженности которых определяет классификационные характеристики игры:

К базовым относится геймплейный уровень, представленный следующими компонентами:

- Рефлексивность - рассудительность: компонент, при высоких значениях характеризующий игры, требующие от пользователя вдумчивого подхода, решения сложных, многоуровневых задач и анализа собственных действий. Низкие показатели присваиваются играм, требующим от игрока бездумной повторяющейся деятельности.

- Сложность геймплейных условий: компонент, определяющий степень сложности условий, предъявляемых игрой. В некоторых играх уровень сложности может устанавливаться самим игроком.

- Когнитивная сложность: компонент, определяющий уровень требований, предъявляемых игрой к когнитивной, интеллектуальной сфере личности игрока.

- Вектор развития персонажа: определяет какой из компонентов: усиление персонажа или развитие навыков самого игрока — оказывает большее влияние на возможность эффективно влиять на мир игры.

- Последствия гибели - уровень неудобств, возникающих у игрока в связи с проигрышем (смертью персонажа и т.д.). Низкому уровню выраженности компонента соответствует игра, в которой проигрыш не влечёт за собой каких-либо неудобств для игрока - он может возобновить процесс. Среднему уровню соответствует игра, в которой проигрыш наказуем, связан с различного рода неудобствами для игрока, например, потерей опыта, длительностью переигровки и т.д. Высокий уровень выраженности компонента характерен для игр, в которых проигрыш ведёт к серьёзным последствиям: немедленному окончанию игры, накоплению счётчика, приближающего к окончанию и т.д.

- Агрессивность - определяет наличие и степень выраженности агрессивных проявлений персонажа. Агрессия в данном случае рассматривается с точки зрения игровой механики.

- Степень погружения определяется геймплейно обусловленным уровнем погружения в персонажа, идентификации с ним. Низкий уровень выраженности компонента предполагает «вид сверху»: игрок берёт на себя роль наблюдателя или закулисного руководителя, при высоком уровне он - персонаж, его действия - от первого лица [2].

- Темп игрового процесса и скорость переключения его эпизодов. При низком уровне выраженности темп игры размерен, игрок шаг за шагом совершает необходимые действия, у него много возможностей для передышки, есть время подумать, в том числе, во время выполнения действий. Среднему уровню соответствует достаточно динамичный процесс игры: этапы высокой активности в равных пропорциях перемешаны с этапами размеренной деятельности. В игре с высоким темпом очень сильна динамика: участков, на которых игрок мог бы передохнуть, практически нет [3]. 
- Игровая направленность: компонент, определяющий то, какой вид игровой деятельности лежит в основе игры.

Вторым базовым является сеттинговый уровень, в него входят следующие компоненты:

- Оживлённость - уровень наполненности игрового мира различными игровыми и неигровыми персонажами. На уровне невыраженности компонента игра не предполагает участие других игроков, враждебных или дружественных NPC (персонажи, управляемые компьютерной программой), Mob (мобильные объекты); на низком уровне отсутствуют Mob-ы, но возможно наличие NPC, с которым игрок не взаимодействует напрямую (общается по рации, слышит голос, вспоминает о взаимодействии и т.д.); при уровне ниже среднего присутствуют Mob-ы, функцией которых является создание безинформационной помощи или помехи для игрока; возможно наличие небольшого количества NPC, как дружественных, так и враждебных; могут участвовать другие игроки. Средний уровень предполагает достаточное количество NPC и Mob-ов, присутствие других игроков. К этой категории можно отнести сессионные онлайн - игры. При уровне выше среднего локации игры густонаселены различными видами NPC, однако стратегии их поведения не отличаются высоким уровнем вариативности и разнообразия. Высокий уровень предполагает, что игровой мир активно живёт, действия каждого NPC в той или иной мере уникальны, стратегии их поведения могут изменяться в зависимости от влияния различных факторов, в том числе, и воздействий самого игрока.

- Враждебность окружения - степень агрессивности игровой среды, в которой оказывается герой, враждебность окружающих его персонажей.

- Реалистичность сеттинга - компонент, который определяет близость среды и условий игрового пространства обстоятельствам реального мира.

- Преобладающая цветовая гамма - определяет, цвета какого спектра чаще встречаются в игре (тёплые - холодные, яркие - бледные, мрачные или красочные, сочетаемые или резко контрастирующие).

- Эмоциональный характер звукового сопровождения: весёлый, энергичный, возбуждающий, успокаивающий, нейтральный, тоскливый, тревожный, пугающий.

- Темпо-ритм звукового сопровождения: компонент определяющий основной темпоритм звукового сопровождения (нормальный, монотонный, сверхдинамичный, монотонно-динамичный) [3].

- Аффектогенность образов персонажей - определяет степень необычности, вычурности и монструозности образов персонажей, демонстрируемых в игре [3].

В отличие от базовых, дополнительные уровни игры вариативны и определяются ее особенностями.

Первой из таких ключевых особенностей является специфика игровой цели. С точки зрения цели мы разделяем игры на три группы:

При условии наличия в игре сюжета возникает возможность для разворачивания смыслового уровня, включающего в себя:

- Ведущий смысл, который определяет поступки игрового персонажа. В случае, если в игре отсутствует сюжет либо же он несёт просто фоновую, оторванную от самой игры функцию (сессионные игры), смыслы реализуются непосредственно самим игроком: эгоцентризм (в основе действий главного героя, лежат эгоистичные мотивы, жажда наживы, месть, ущемлённое самолюбие), группоцентризм (персонаж принимает решения основываясь на интересах его ближайшего окружения; гуманизм (персонаж руководствуется интересами большого числа людей, зачастую во вред себе) [4].

- Основной внутриигровой мотиватор агрессии: наличие и характер основного мотиватора, подталкивающего персонажа к агрессивным проявлениям. Выраженность этого компонента в играх варьирует от полного отсутствия, когда в игре нет элементов

International Culture \& Technology Studies, Vol. 3, No. 4 
агрессивного поведения персонажа, через типы «защита» (игрок вынужден проявлять агрессию, защищая своего или дружественного персонажа, и такое поведение не поощряется сторонними факторами: деньгами, опытом, вещами)) и «защита/нападение»: игрок выступает защитником, однако агрессия также мотивированна другими факторами (личной выгодой) - до характеризующего высокий уровень выраженности «нападения»: игрок выступает агрессором, и такое поведение мотивируется идеологически либо поощряется при помощи сторонних факторов (деньги, опыт, вещи и т.д.)

Наличие сюжета также определяет проявление нарративного уровня, к которому мы относим следующие компоненты:

- Осознанность внутриигровой цели: степень осознанности, персонажем и игроком своей конечной цели, её мотивационного аспекта, а также понимание путей её достижения.

- Масштаб последствий принятых решений: степень выраженности компонента определяет значение последствий влияния решений игрока на ход игры. При невыраженности показателя у игрока нет возможности принимать самостоятельные решения либо они не влияют на ход игры; при низком уровне последствия несущественны, несут «косметический» характер: внешний вид героя и его окружения, некоторые геймплейные изменения. Средний уровень выраженности предполагает, что последствия принимаемых решений влияют на отношение к герою, вносят некоторые корректировки в сюжет. В играх с высокой выраженностью компонента каждое решение может вести за собой далеко идущие последствия, коренным образом влияя на игровой сюжет.

- Осознанность последствий принятых решений: наличие у игрока возможности посредством принимаемых решений влиять на происходящие в игре события, степень очевидности последствий принимаемых решений.

- Критерий логической завершённости определяет, является ли игра законченным произведением, имеющим как начало, так и логическое завершение, или же представляет из себя бесконечный аттракцион, в который игрок может погрузиться на годы.

- Событийная насыщенность. Выраженность этого компонента определяется степенью наполненности игрового процесса уникальными событиями. Компонент не выражен в играх, где присутствует только рутинный геймплей, без каких-либо значимых событий. При низком уровне выраженности рутинный геймплей превалирует, но иногда происходят уникальные сюжетные и геймплейные события. Среднему уровню соответствует игра с достаточным количеством уникальных событий, равномерно распределённых на протяжении всей игры. В игре с высоким уровнем выраженности компонента значительна концентрация уникальных событий, рутинный геймплей практически отсутствует, либо события происходят на его фоне.

Проявление личностного уровня зависит от наличия в игре протагониста с прописанной личностью, обладающего своим характером, проявляющимся в процессе игры. Данный уровень включает в себя следующие компоненты:

- Эмоциональный фон - определяет преобладающий спектр эмоциональных состояний персонажа, может быть отрицательным, нейтральным и положительным.

- Степень выраженности эмоций главного героя - сила выраженности эмоциональных переживаний главного героя.

- Сила влияния Я - возможности влияния персонажа на игровой мир. При низком уровне выраженности этого компонента герой не в состоянии повлиять на происходящие события, он только наблюдатель. Высокому уровню соответствует игра, в которой герой может добиться всего, что входит в его планы. Рассматриваются также промежуточные (ниже среднего, средний, выше среднего) варианты. 
- Нравственный облик главного героя - его характеристика с точки зрения нравственных и моральных принципов

- Нравственная динамика главного героя. Выраженность этого компонента в игре дифференцируется от «деградации» (с течением времени игры и согласно ее логике персонаж проявляет всё больше отрицательных черт, демонстрируя жадность, безволие, мстительность, безразличие к другим живым существам и т.д.), через «стабильность» (на протяжении игры нравственный облик главного героя не претерпевает изменений) к «развитию» (персонаж развивается, учится бороться со своими страхами и слабостями, становятся более отзывчивым и терпеливым, становится лучше).

Проявление межличностного уровня связано с наличием возможности сетевой игры. К компонентам, входящим в этот уровень, относятся:

- Возможность коммуникации с другими игроками, степень необходимости этого взаимодействия. Уровень выраженности определяется от низкого однопользовательской игры через несколько промежуточных уровней до высокого, когда взаимодействие между игроками является одной и ведущих игровых механик, вокруг нее строится геймплей.

- Характер коммуникации с другими игроками - определяет основной тип взаимодействия между игроками: сотрудничество, вражда и разнообразное.

Морально-нравственный уровень, в отличие от других дополнительных уровней, не зависит от наличия каких-либо особенностей игры, возможность его проявления присуща всем играм. В его состав входят следующие компоненты:

- Жестокость - определяет наличие, выраженность жестокости и степень её реалистичности и изощрённости [3].

- Гуманность - определяется, исходя из того, на какое поведение игрока провоцируют условия игры. Поощряются ли проявления гуманизма или же, наоборот, вознаграждается эгоистичное и насильственное поведение.

Дробность структурного дизайна представленной модели позволяет анализировать игры разных типов, что представляется важной задачей, решение которой позволит более предметно дифференцировать игры для определения особенностей влияния игровой активности на игрока в разных виртуальных обстоятельствах.

\section{Литература}

[1] Тимофеев С.Б. Психологические классификации компьютерных игр // Психолого-социальная работа в современном обществе: проблемы и решения: материалы международной научно-практической конференции, 19-20 апреля 2018 года / под общ. ред. Ю.П. Платонова. СПб.: СПбГИПСР, 2018. С. 274277.

[2] Смирнова Е.О., Радева Р.Е. Психологические особенности компьютерных игр: новый контекст детской субкультуры // Образование и информационная культура. Социологические аспекты. Труды по социологии образования. Т. V. Вып. VII. М.: Центр социологии образования РАО, 2000. С. 330-369.

[3] Пронина Е. Е. Психологическая экспертиза рекламы. Теория и методика психотехнического анализа рекламы. М, 2000. С. 96.

[4] Братусь Б.С. Аномалии личности. М.: Мысль, 1988. 


\title{
Psychological classification of computer games
}

\author{
I. Kychtymova, S. Timofeev
}

Irkutsk State University

\begin{abstract}
The authors define a computer game as a multilevel and multicomponent system, the components and levels of which may have varying degrees of connections tightness. Based on this, it is suggested that classifications that concentrate on separate components of the game are not effective enough to study the comprehensive influence of specific games on the personality. Analyzing available computer game classifications, the authors come to the conclusion that there is no universal classification construct that allows performing a comprehensive differentiated analysis of computer games in order to determine the specific features of their psychological impact on gamers. The proposed classification model consists of weakly connected components. The presence of these components is inherent in most existing games, but the degree of their expression can vary. The levels include thirty-two components, the degree of which can determine the classification characteristics of the game.
\end{abstract}

Keywords: computer game, classification, system, components, gamer

\section{References}

[1] Timofeev S.B. Psihologicheskie klassifikacii komp'yuternyh igr [Psychological classifications of computer games] // Psihologo-socialnaya rabota v sovremennom obshchestve: problemy i resheniya: materialy mezhdunarodnoj nauchno-prakticheskoj konferencii, 19-20 aprelya 2018 goda / pod obshch. red. YU.P. Platonova [Psychological and social work in modern society: problems and solutions: materials of the international scientific and practical conference, April 19-20, 2018 / under total. Ed. Yu.P. Platonov]. SPb.: SPbGIPSR, 2018. S. 274-277.

[2] Smirnova E.O., Radeva R.E. Psihologicheskie osobennosti kompyuternyh igr: novyj kontekst detskoj subkul'tury [Psychological features of computer games: a new context for children's subculture] // Obrazovanie i informacionnaya kul'tura. Sociologicheskie aspekty. Trudy po sociologii obrazovaniya. T. V. Vyp. VII [Education and information culture. Sociological aspects. Proceedings on the sociology of education. Vol. V. Iss. VII]. M.: Centr sociologii obrazovaniya RAO [Center for Sociology Education of RAO], 2000. S. 330-369.

[3] Pronina E. E. Psihologicheskaya ehkspertiza reklamy. Teoriya i metodika psihotekhnicheskogo analiza reklamy [Psychological examination of advertising. Theory and methodology of psychotechnical analysis of advertising]. M, 2000. S. 96.

[4] Bratus' B.S. Anomalii lichnosti [Anomalies of personality]. M.: Mysl [Think]', 1988. 